\title{
Morphologic and morphometric characteristics of the adductor minimus in Korean: its topographic relationship with respect to neighbouring anatomical structure and clinical significance
}

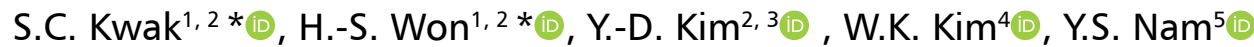 \\ ${ }^{1}$ Department of Anatomy, Wonkwang University School of Medicine, Iksan, Republic of Korea \\ 2Jesaeng-Euise Clinical Anatomy Centre, Wonkwang University School of Medicine, Iksan, Republic of Korea \\ ${ }^{3}$ Department of Anaesthesiology and Pain Medicine, Wonkwang University School of Medicine, \\ Wonkwang University Hospital, Iksan, Republic of Korea \\ ${ }^{4}$ Department of Anatomy and Cell Biology, College of Medicine, Hanyang University, Seoul, Republic of Korea \\ ${ }^{5}$ Department of Anatomy and Catholic Institute for Applied Anatomy, College of Medicine, The Catholic University \\ of Korea, Seoul, Republic of Korea
}

[Received: 25 July 2020; Accepted: 27 August 2021; Early publication date: 3 September 2021]

Background: The aim of this study was to clarify the morphologic and morphometric characteristics of the adductor minimus (AMi) and to observe its topographic relationships relative to the adjacent anatomical structures.

Materials and methods: This study investigated 54 thighs of 27 Korean cadavers. Results: The AMi was a small and flat muscle observed in $94.4 \%$ of the specimens. It originated from the inferior ramus of the pubis as the upper part of the adductor magnus ( $\mathrm{AMa}$ ), and inserted from the lesser trochanter to the upper part of the linea aspera. The AMi was completely separate from the AMa in $63.0 \%$ of the specimens. The medial circumflex femoral artery was always found at the superior border of the AMi, while the first and second perforating arteries were found inferior to the muscle in $55.6 \%$ and $37.0 \%$ of specimens, respectively. A supernumerary muscle was found with the AMi in $42.6 \%$ of the specimens, and it originated from the inferior ramus of the pubis and inserted into the posterior side of the lesser trochanter. The obturator externus and AMi were found superoposterior and inferior to the supernumerary muscle, respectively, while the posterior branch of the obturator nerve passed underneath it.

Conclusions: The results of this study may provide physicians with the accurate anatomical knowledge that they require for managing groin pain and applying a regional nerve block with ultrasound guidance in this adductor region. (Folia Morphol 2021; 80, 4: 963-971)

Key words: adductor magnus, cadaver, obturator nerve block, ultrasound, variation 


\section{INTRODUCTION}

The obturator nerve arises from the anterior rami of spinal nerves L2 to L4 in the lumbar plexus, and descends to the thigh via the obturator canal. This nerve divides into two main branches near the canal: an anterior branch and a posterior branch. The anterior branch runs anterior to the obturator externus and descends in front of the adductor brevis, behind the pectineus and adductor longus. The posterior branch pierces the obturator externus anteriorly, and passes between the adductor brevis and magnus (AMa) [8]. Various abnormal conditions such as tumour, hernia, and aneurysm could cause an entrapment syndrome at any point along the entire course of the obturator nerve [5]. The chief complaints of patients with such entrapment of the obturator nerve are numbness and sensory loss of the medial thigh, sometimes involving the calf. Weakness of leg adduction can also occur, as well as pain in the groin and medial thigh $[5,49]$. Such pain is reportedly worsened by extension or rotation of the lower leg that stretches the nerve [11].

For both diagnosis and treatment when managing this symptom, obturator nerve block (ONB) has been commonly adapted to each branch under guidance provided by real-time ultrasound (US) imaging [12, $43,47,52]$.The block for the anterior branch is induced by injecting a local anaesthetic between the pectineus and adductor brevis [12, 43], while the posterior branch is blocked by injecting between the adductor brevis and AMa [47]. During this procedure, the existence of the adductor minimus (AMi) or supernumerary muscle (SM) needs to be considered for avoiding confusion about the final position of the tip of the injection needle, especially for inexperienced operators. Thus, an accurate knowledge of the muscle layers in the target region is essential to successfully achieving nerve blocks.

This study was designed to clarify the topographic relationships among the $\mathrm{AMi}, \mathrm{SM}$, and adjacent structures such as arteries, bone, and other muscles in the adductor region, with the aim of facilitating the diagnosis and treatment using ONB.

\section{MATERIALS AND METHODS}

Fifty-four thighs of 27 embalmed Korean adult cadavers (20 males, 7 females; mean age at death, 71.6 years; age range at death, 48-87 years) were investigated for this study. All of the cadavers used in this study had been legally donated to the Catholic
University of Korea, and all of the research procedures were performed in accordance with the Helsinki Declaration. None of the cadavers showed any evidence of gross pathologies, previous surgical procedures, or traumatic lesions to the thigh region. This study was not subject to a review by the institutional review board (IRB) because of a cadaveric study that did not any personal identifiable information, which was confirmed by the IRB of the Catholic University of Korea (No. CHRPP CR-08).

All muscles of the thigh were exposed after removing the skin, subcutaneous tissue, and fascia lata. The sartorius and adductor longus were cut to check for the presence of the AMi and SM. If they were found, the target muscles and adjacent anatomical structures were carefully dissected without changing their locations. Chi-square test was used to compare the incidence of a SM between two genders and between both sides, with a statistical significance level of $p<0.05$.

\section{RESULTS}

The AMi formed the upper part of the AMa, and its muscle fibres ran more horizontally than those of the AMa (Fig. 1). This muscle originated from the inferior pubic ramus, and inserted between the lesser trochanter and the upper part of the linea aspera, corresponding to the proximal one-fourth of the distance from the lesser trochanter to the adductor tubercle (Fig. 2). The portions where the muscle attached to the pubic ramus and femur were $3.2 \pm 0.7 \mathrm{~cm}$ and $7.7 \pm 2.0 \mathrm{~cm}$ long (mean \pm standard deviation), respectively. The AMi was observed in $94.4 \%$ of the specimens. This muscle was completely separate from the AMa in $63.0 \%$ of the specimens, and could be distinguished but not as a separate muscle in $31.5 \%$ of them (Table 1). In the former cases, the inferior part of the muscle partly overlapped the AMa (by $2.8 \pm$ $\pm 1.9 \mathrm{~cm}$ ) at its insertion portion (Figs. 2C; 3). In the latter cases, the insertion portions of both muscles were continuously connected with each other.

The medial circumflex femoral artery was always found at the superior border of the AMi. The inferior border of the muscle was bounded by three kinds of the arteries (Fig. 4): the first perforating artery (55.6\% of the specimens), the second perforating artery (37.0\%), and the muscular branch of the deep femoral artery (7.4\%).

A triangular shaped SM was observed in $42.6 \%$ of the specimens, which was located posterior to the 

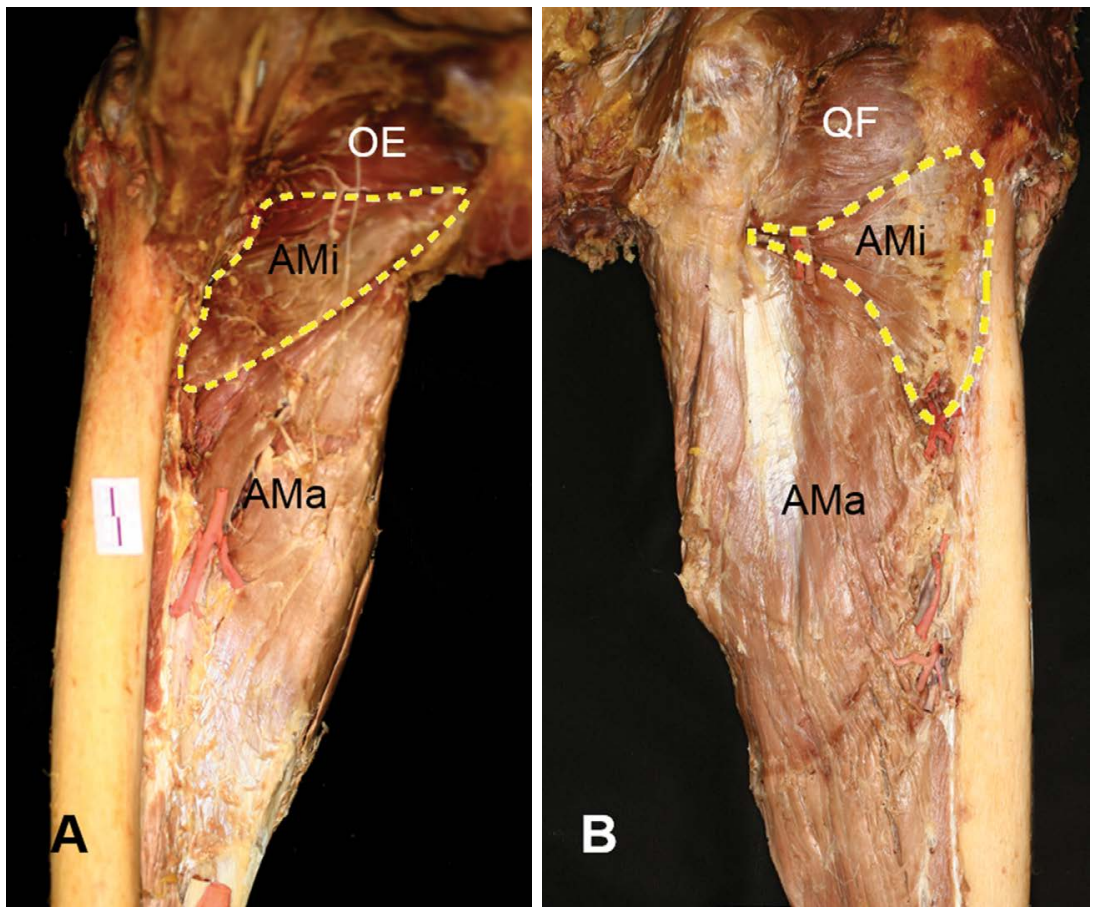

Figure 1. Anterior (A) and posterior (B) views of the adductor minimus. All muscles in the thigh except the obturator externus (OE), quadratus femoris ( $\mathrm{QF}$ ), adductor minimus (AMi), and adductor magnus (AMa) were removed. Dashed lines indicate the boundaries of the adductor minimus.

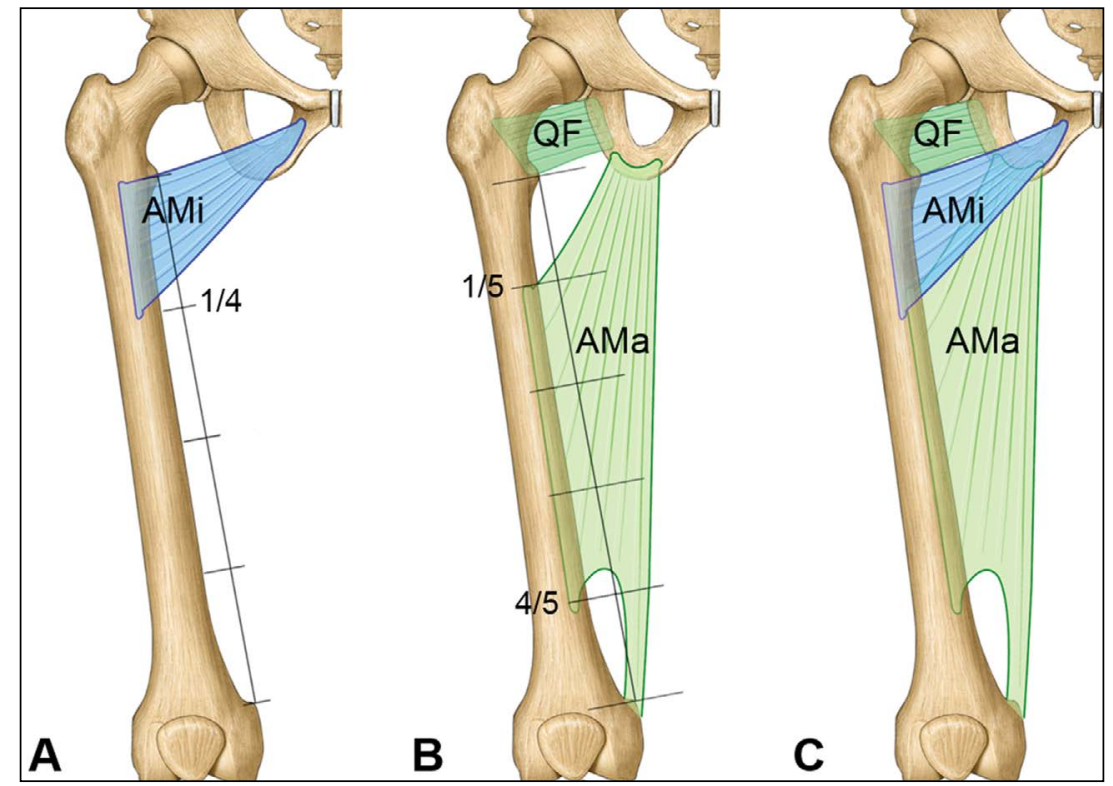

Figure 2. Schematic drawings of the topographic relationships among the adductor minimus (AMi), adductor magnus (AMa), and quadratus femoris (OF); A. The adductor minimus is attached to the proximal one-fourth of the distance from the lesser trochanter to the adductor tubercle; $\mathbf{B}$. The adductor magnus is attached to the distal four-fifths of this distance; $\mathbf{C}$. The adductor minimus is inferior to the $\mathrm{OF}$ and superior to the adductor magnus, and some parts of the adductor minimus an adductor magnus overlap.

adductor brevis, superior to the AMi, inferoanterior to the obturator externus, and anterior to the posterior branch of the obturator nerve (Fig. 5). The incidence of a SM did not differ between males and fe- males, and between the right and left sides (Table 2). This muscle originated from the inferior pubic ramus and inserted into the posterior side of the lesser trochanter. 


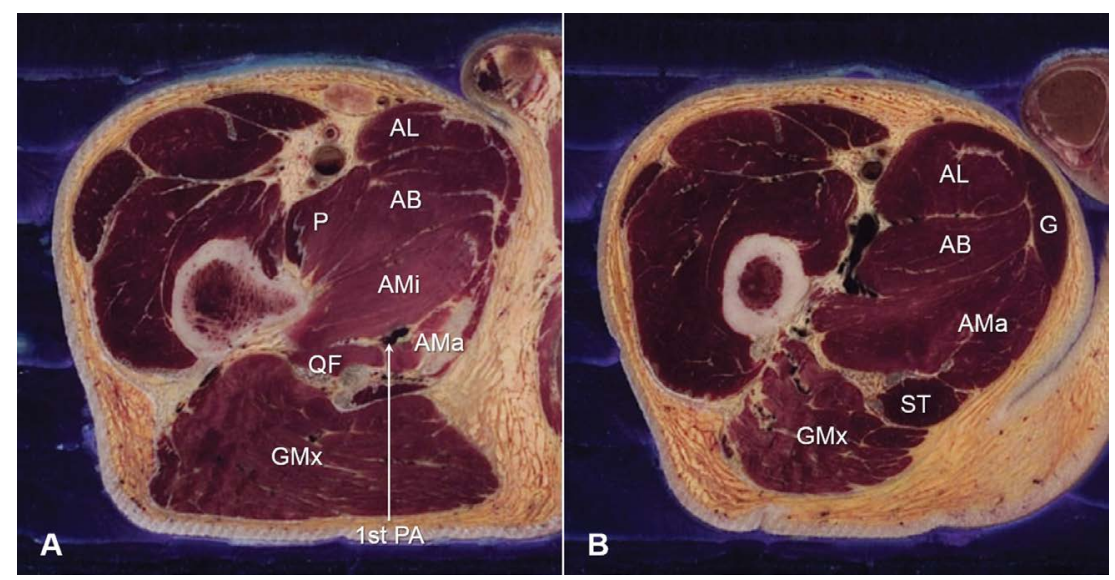

Figure 3. Cross-section images showing the adductor minimus (AMi) obtained from the Visible Human Korean project; A. The adductor minimus overlaps the adductor magnus (AMa) at the proximal one-fourth of the thigh. The adductor minimus can be distinguished from the adductor magnus by the first perforating artery $\left(1^{\text {st }} \mathrm{PA}\right)$; $B$. The adductor minimus disappears below the $1^{\text {st }} \mathrm{PA}$, with only the adductor magnus being visible; $\mathrm{AL}$ — adductor longus; $\mathrm{AB}$ — adductor brevis; P — pectineus; $\mathrm{GMx}$ - gluteus maximus; $\mathrm{G}$ — gracilis; $\mathrm{ST}$ — semitendinosus.

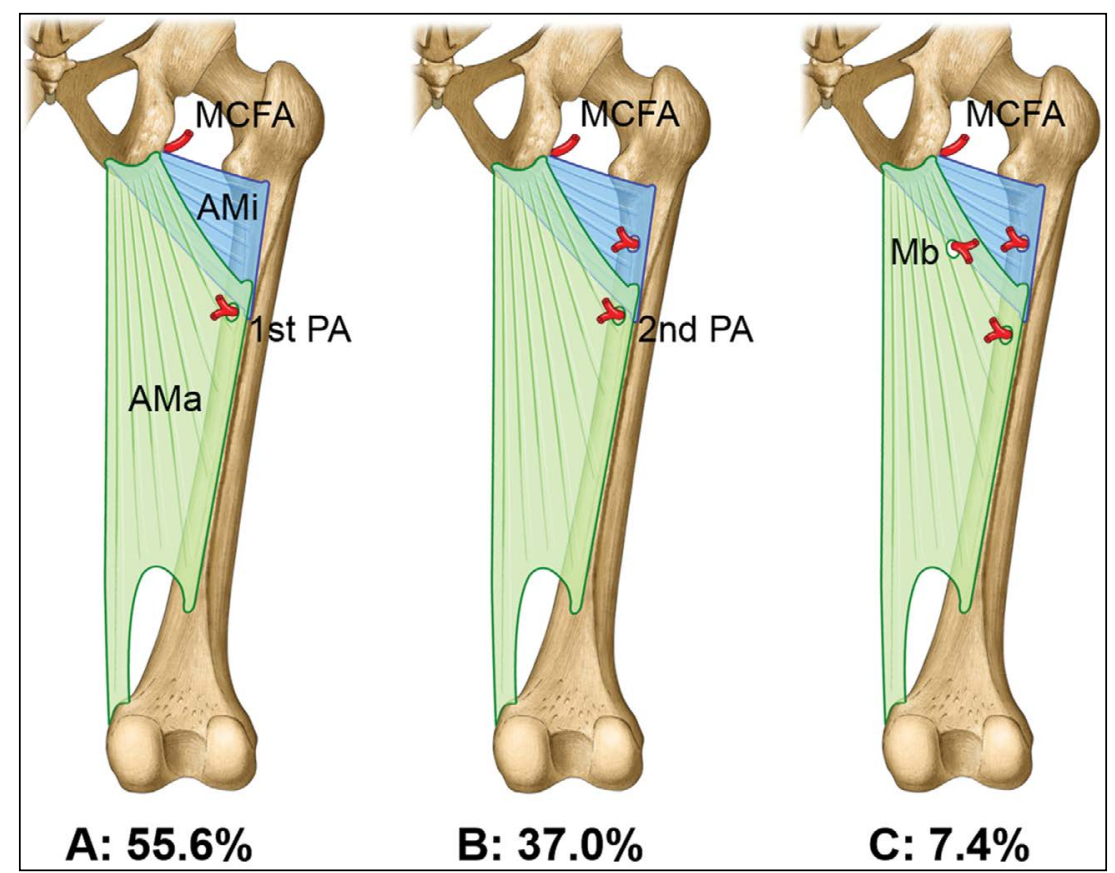

Figure 4. Structures that can help to distinguish the superior and inferior borders of the adductor minimus (AMi), and their prevalence rates; A. The medial circumflex femoral artery (MCFA) and the first perforating artery $\left(1^{\text {st }} \mathrm{PA}\right)$; $\mathbf{B}$. The MCFA and the second perforating artery $\left(2^{\text {nd }} \mathrm{PA}\right) ;$ C. The MCFA and the muscular branch of deep femoral artery $(\mathrm{Mb}) ; \mathrm{AMa}$ — abductor magnus.

\section{DISCUSSION}

Since ONB was first introduced by Labat and Mayo in 1922, it has been adapted for the management of various conditions [16]. This type of nerve block can prevent abnormal contraction of the thigh muscles during the ablation of bladder tumours [34], relax adductor muscle spasm secondary to paraplegia [23], and provide postoperative pain management
[20]. Moreover, it can be applied to manage acute or chronic pain in the groin and thigh, since the obturator nerve is at risk of entrapment, compression, and damage at many sites related to surgery and trauma [22]. US-guided ONB has recently been regarded as the optimal technique. This type of block is safe, cost-effective, and makes it possible to observe the position of the injection needle in real time, which 


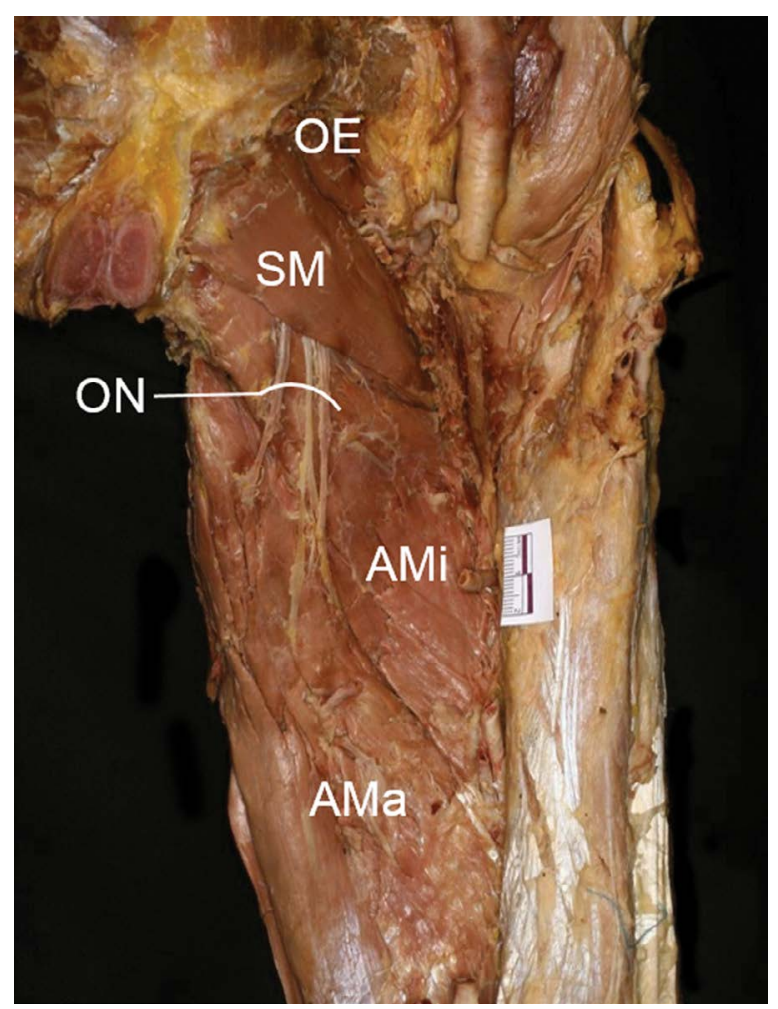

Figure 5. Anterior view of a supernumerary muscle (SM). The adductor longus and adductor brevis were removed to expose the SM and adjacent muscles. The SM is superior to the adductor minimus (AMi) and inferoanterior to the obturator externus (OE). The posterior branch of the obturator nerve (ON) passes behind the SM; $\mathrm{AMa}$ - abductor magnus.

can reduce the amount of local anaesthetic that needs to be administered, the risk of systemic toxicity, and the block onset delay [3, 48].

Numerous studies have attempted to provide exact information about the structures in US images through cadaver dissections in this region [4, 35, 53]. Nonetheless, US-guided ONB is not always successful $[25,43]$. The likelihood of success can be influenced by various factors including the physician's experience, the patient's condition, and the performance of the US imaging system, similarly to the situation for other types of block [17]. Anatomical features such as the presence of unexpected muscles or the accessory obturator nerve in this region might also affect the likelihood of success [42].

There are two kinds of muscles being able to confuse physicians in the adductor region through reviews of the previous literatures: the AMi and SM. The AMi is small, flat, and can be distinguished at the posterior part of the adductor brevis and the upper part of the AMa [50]. This muscle originates
Table 1. Different types of the adductor minimus and their frequencies in the present study

\begin{tabular}{lccc}
\hline & Males, \% & Females, \% & Total, \% \\
\hline Separate & $50(\mathrm{n}=27)$ & $13(\mathrm{n}=7)$ & $63(\mathrm{n}=34)$ \\
Distinguishable & $20.4(\mathrm{n}=11)$ & $11.1(\mathrm{n}=6)$ & $31.5(\mathrm{n}=17)$ \\
Absent & $3.75(\mathrm{n}=2)$ & $1.9(\mathrm{n}=1)$ & $5.6(\mathrm{n}=3)$ \\
Total & $74.1(\mathrm{n}=40)$ & $25.9(\mathrm{n}=14)$ & $100(\mathrm{n}=54)$ \\
\hline
\end{tabular}

Table 2. Frequency of the supernumerary muscle in males and females and on the left and right sides in the present study

\begin{tabular}{lcccc}
\hline & Males, \% & Females, \% & Right, \% & Left, \% \\
\hline Present & $42.5(n=17)$ & $42.9(n=6)$ & $55.6(n=15)$ & $29.6(n=8)$ \\
Absent & $57.5(n=23)$ & $57.1(n=8)$ & $44.4(n=12)$ & $70.4(n=19)$ \\
Total & $100(n=40)$ & $100(n=14)$ & $100(n=27)$ & $100(n=27)$ \\
\hline
\end{tabular}

Table 3. Frequency of the adductor minimus in different studies

\begin{tabular}{lccc}
\hline Study & Population & Specimens & Per cent \\
\hline Mori (1964) & Japanese & 50 & $92 \%$ \\
Tubbs et al. (2011) & American & 40 & $52.5 \%$ \\
Gusmão et al. (2014) & Brazilian & 40 & $32 \%$ \\
This study (2020) & Korean & 54 & $94.4 \%$ \\
\hline
\end{tabular}

predominantly from the inferior ramus of the pubis [50] or the ischiopubic ramus [15] and inserts into the femur, and is innervated by the obturator nerve. The descriptions of the origin and insertion of the muscle are broadly consistent in the anatomical literature, whereas those related to distinguishing the muscle have been inconsistent: some authors have regarded this muscle as the upper part of the AMa [9, 26, 39, 41], while others have suggested that it is independent of adjacent muscles [6, 10,36]. Some textbooks do not even mention this muscle at all $[2,27,37]$. The AMi is normally present in apes such as gorillas and chimpanzees [30], while its incidence in humans has been reported as $32 \%$ to $92 \%$ of the specimens according to the different populations $[15,28,50]$ (Table 3). The present study found that its incidence was $94.4 \%$ in Korean cadavers, which was similar to that in the previous study using same race [28]. In the human embryo, the AMa arises as two distinct parts that subsequently fuse to form the muscle in the adult. This means that the AMi could appear to be present when two distinct parts of the AMa do not fuse completely [30]. In addition, the function of 
Table 4. Frequency of the supernumerary muscle in different studies

\begin{tabular}{lccc}
\hline Study & Population & Specimens & Per cent \\
\hline Abe (1964) & Japanese & 98 & $11.2 \%$ \\
Nakamura et al. (1992) & Japanese & 100 & $33 \%$ \\
Yatsunami et al. (2004) & Japanese & 73 & $23.3 \%$ \\
This study (2020) & Korean & 54 & $42.6 \%$ \\
\hline
\end{tabular}

the AMi has been reported that it is not totally same with that of the AMa by a previous electromyographic study [7]. Both of these muscles show the highest activities during the maximal resisted extension of the hip joint, and have also the moderate activities during maximal hip adduction. However, the AMi is more active than the AMa during external rotation of hip joint. The AMi has also been suggested that it could be used as a landmark for identifying the posterior extent of the medial femoral circumflex artery and the first perforating artery for vascular anastomosis or for avoiding vascular structures [50]. In the present study, the medial circumflex femoral artery was always found at the superior border of the AMi, whereas the first perforating artery was only found at the inferior border of the muscle in $55.6 \%$ of the specimens. Thus, other arteries should also be considered when identifying the inferior border of the muscle, such as the second perforating artery and the muscular branch of the deep femoral artery, which were found in $37 \%$ and $7.4 \%$ of the present cases, respectively (Fig. 4).

A SM can be found between the adductor brevis and AMi, which has been reported as an anomalous muscle belonging to the adductor brevis [1] or the obturator externus [51]. This muscle is innervated by the posterior branch of the obturator nerve [29, 51], and its reported incidence has ranged from $11.2 \%$ to $33 \%$ in Japanese adults $[1,29,51]$ (Table 4 ). Nakamura et al. [29] found that this muscle arose from the inferior ramus of the pubis and attached to the aponeurosis of AMi in $51.5 \%$ of their specimens, to the upper part of the pectineal line $(27.3 \%)$, or to the posterior side of the base of the lesser trochanter $(21.2 \%)$. In the present study, this muscle was observed posterior to the adductor brevis, superior to the $\mathrm{AMi}$, and inferoanterior to the obturator externus. Its incidence was $42.6 \%$, which is higher than in previous studies. Moreover, in all cases this muscle originated from the inferior pubic ramus, and inserted simply into the posterior side of the lesser trochanter. Peiris et al. [32] insisted that the greater cross-sectional area of hip adductors could be related to the better function and quality of life in patients with hip osteoarthritis. The SM located between the adductor brevis and AMi in the present cases might affect this kind of cross-sectional area, which will need to be revealed through the other study.

Various SMs are frequently found in the upper and lower limbs, thoracic wall, neck, face, and eye, which include three-headed biceps brachii [40], pronator teres accessories [21], adductor accessories [13], pectoralis quartus [46], supernumerary digastric muscle [44], gracillimus orbitis muscle [19], and supernumerary extraocular muscle [33], with their embryologic origins also being hypothesized. The limbs first develop as the upper and lower limb buds, which are formed at levels C4-T2 and L2-S2, respectively [38]. Further development of the limb buds occurs via a series of stages including outgrowth, rotation, and the regional singular growth of structures [31]. The limb musculature develops from the paraxial mesoderm, and in the $7^{\text {th }}$ week of development appears as the condensation of mesenchyme near the base of the limb buds [38]. The elongation of the limb buds results in the muscle tissue splitting into flexor and extensor components, which then fuse and form a single muscle mass [14]. In humans, the embryologic development of the adductor group of the thigh is first evident in the proximal region of an 11-mm-long embryo (approximately at a gestational age of early during week 6 ), with the separation into independent masses for the different muscles of the group. These separate muscles are evident once the embryo length reaches $14 \mathrm{~mm}$ (late during week 6), and at $20 \mathrm{~mm}$ long (week 7) the muscles of the adductor compartment are clearly discernible [18]. The lower limb rotates $90^{\circ}$ medially between the $6^{\text {th }}$ and $8^{\text {th }}$ weeks of gestation [38]. While the limb musculature is differentiating, some muscle cells undergo apoptosis that determines the normal shape or the variations in the growing muscles and muscular compartments [24]. The SM in the present study was found in the medial thigh and located posterior to the adductor brevis, superior to the AMi, and inferoanterior to the obturator externus. Although the exact mechanisms of the formation of this muscle remain to be revealed, they might originate from the persistence of cells not undergoing the process of cell death [45] or abnormal $90^{\circ}$ medial rotation of the lower limb bud [31]. 


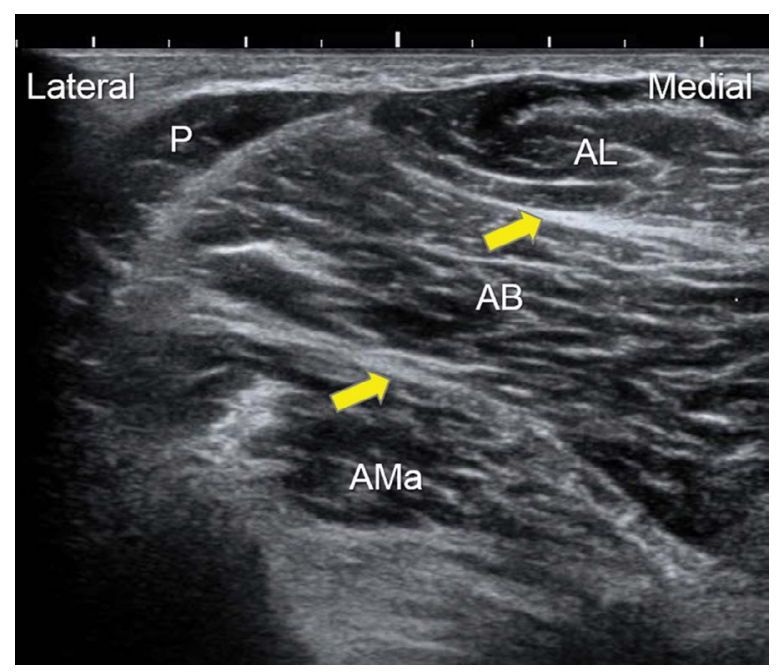

Figure 6. A patient ultrasound image (Linear probe $12-5 \mathrm{~Hz}$, Samsung HS 60, Samsung Medison, Korea) showing the interfascial plane between the adductor longus (AL) and adductor brevis ( $A B)$ and between the adductor magnus ( $\mathrm{AMa}$ ) and $\mathrm{AB}$. Arrows indicate the injection points for the anterior and posterior divisions of the obturator nerve (ON); $\mathrm{P}$ - pectineus.

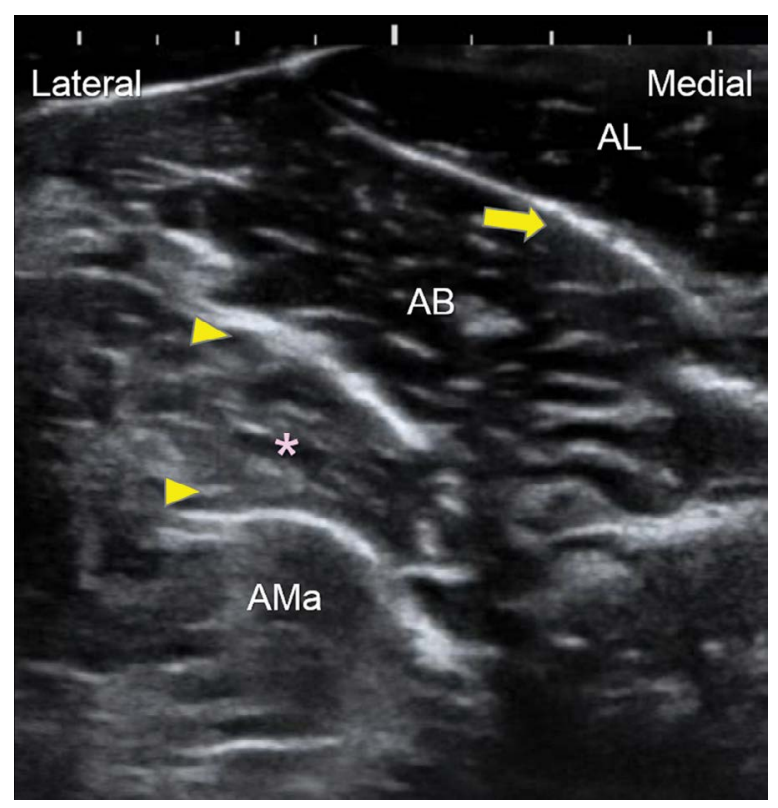

Figure 7. A patient ultrasound image (Linear probe $12-5 \mathrm{~Hz}$, Samsung HS 60, Samsung Medison, Korea) showing a case that might confuse the physician during ultrasound-guided obturator nerve block. The arrow indicates the injection point for the anterior division of the obturator nerve. Arrowheads indicate structures mimicking the posterior division of the obturator nerve. The asterisk indicates either an adductor minimus or a supernumerary muscle; $\mathrm{AL}$ — adductor longus; $\mathrm{AB}$ — adductor brevis; $\mathrm{AMa}$ — adductor magnus.

Regarding clinical practice, the techniques used by physicians performing US-guided ONB can be classified into distal or proximal approaches based on the position of the US transducer. A common method for US-guided ONB involves the distal approach, in which the anterior and posterior divisions of the obturator nerve are blocked separately by two injections of local anaesthetic directed toward the interfascial planes [12]. The adductor brevis is located between the anterior and posterior divisions of the obturator nerve in the thigh, and these two divisions of the nerve are thin and flat as the fascicles disperse to the muscle groups [47]. The interfascial plane for the adductor muscle group could be identified based on two hyperechoic lines superficial and deep to the adductor brevis muscle in the present US images (Fig. 6), whereas the presence of the obturator nerve could not be confirmed. Thus, when performing a US-guided ONB it is recommended that the physician employs an interfascial injection to block each branch of the obturator nerve [43]. However, these interfascial planes sometimes can be confused (Fig. 6), especially in patients who are morbidly obese or who have structural abnormalities related to trauma or surgery, which could lead to an incomplete block. In addition, the existence of the AMi or SM can also result in physicians performing misguided injections because they cannot decide about the exact presence or location of a facial plane for ONB (Fig. 7). In this condition, US-guided ONB with nerve stimulation is recommended for ensuring a successful procedure.

\section{CONCLUSIONS}

This is the first study to reveal the existence frequencies of the AMi and SM in the Korean population, and also to address clinical considerations with respect to the layering of these muscles. The authors expect that these results will help physicians to decide about the ideal injection point in US-guided ONB. However, this study had the limitations that it was not possible to accurately determine the procedure success rate or the optimal amount of local anaesthetic for US-guided ONB in the target area, because it had an observational design and involved fixed cadavers. Future studies should investigate fresh cadavers using dye injection based on this study, and perform clinical trials in living patients referring to those results. 


\section{Acknowledgements}

The study was supported by Wonkwang University in 2020. The authors deeply appreciate the body donors and their families who participated in the donation programme of College of Medicine, The Catholic University of Korea, and thank Prof. Min-Suk Chung at the Aju University College of Medicine for providing high-quality photographs related to the Visible Human Korean project.

\section{Conflict of interest: None declared}

\section{REFERENCES}

1. Abe K. [Variation of m.adductor brevis]. Kaibogaku Zasshi. 1964; 39: 232-234, indexed in Pubmed: 14199759.

2. Agur AMR, Lee MJ. Grant's Atlas of Anatomy. 10th ed. Lippincott Williams \& Wilkins, Philadelphia 1999.

3. Akkaya T, Ozturk E, Comert A, et al. Ultrasound-guided obturator nerve block: a sonoanatomic study of a new methodologic approach. Anesth Analg. 2009; 108(3): 1037-1041, doi: 10.1213/ane.0b013e3181966f03, indexed in Pubmed: 19224822.

4. Anagnostopoulou S, Kostopanagiotou G, Paraskeuopoulos $\mathrm{T}$, et al. Anatomic variations of the obturator nerve in the inguinal region: implications in conventional and ultrasound regional anesthesia techniques. Reg Anesth Pain Med. 2009; 34(1): 33-39, doi: 10.1097/ AAP.0b013e3181933b51, indexed in Pubmed: 19258986.

5. Anderson-Jones SR. Lower Extremity. In: Trescot AM (ed.). Peripheral Nerve Entrapments: Clinical Diagnosis and Management. Springer, Switzerland 2016: 615-881.

6. Anson BJ. An Atlas of Human Anatomy. 2nd ed. WB Saunders, Philadelphia 1963.

7. Benn ML, Pizzari T, Rath L, et al. Adductor magnus: An EMG investigation into proximal and distal portions and direction specific action. Clin Anat. 2018; 31(4): 535-543, doi: 10.1002/ca.23068, indexed in Pubmed: 29520841.

8. Berry MM, Standring SM, Bannister LH. Nervous System. In: Williams PL (ed.). Gray's Anatomy. 38th ed. Churchill Livingstone, New York 1995: 901-1397.

9. Bouchet A, Cuilleret J. Anatomie: Topographique Descriptive et Functionnelle. 2nd ed. Simep, Paris 1990.

10. Brizon J, Castaing J. Les Feuillets D'anatomie: Muscles Du Membre Inférieur. 2nd ed. Maloine, Paris 1997.

11. Busis NA. Femoral and obturator neuropathies. Neurol Clin. 1999; 17(3): 633-653, doi: 10.1016/s07338619(05)70156-0.

12. Fujiwara $Y$, Sato $Y$, Kitayama $M$, et al. Obturator nerve block using ultrasound guidance. Anesth Analg. 2007; 105(3): 888-889, doi: 10.1213/01.ane.0000268517.37921.ef, indexed in Pubmed: 17717272.

13. Goel S, Arora J, Mehta V, et al. Adductor accessorius: an unusual supernumerary adductor muscle of thigh. Clin Ter. 2015; 166(3): 114-117, doi: 10.7417/CT.2015.1840, indexed in Pubmed: 26152618.

14. Grigoriță L, Gug C, Vaida MA, et al. An unusual case of unilateral supernumerary extensor carpi radialis muscle.
Folia Morphol. 2019; 78(4): 888-892, doi: 10.5603/ FM.a2019.0037, indexed in Pubmed: 30949998.

15. Gusmão L, Lima JB, Santos ML, et al. Músculo Aductor Mínimo en Individuos Brasileños. Int J Morphol. 2014; 32(2): 440-443, doi: 10.4067/s0717-95022014000200010.

16. Hadzic A. Textbook of Regional Anesthesia and Acute Pain Management. 2nd ed. McGraw-Hill Education, New York 2017.

17. Huang J, Li J, Wang $\mathrm{H}$. The principles and procedures of ultrasound-guided anesthesia techniques. Cureus. 2018; 10(7): e2980, doi: 10.7759/cureus.2980, indexed in Pubmed: 30237941.

18. Jeno SH, Schindler GS. Anatomy, bony pelvis and lower limb, thigh adductor magnus muscles. StatPearls Publishing, Treasure Island 2018.

19. Jordan DR, Stoica B. The gracillimus orbitis muscle. Ophthalmic Plast Reconstr Surg. 2017; 33(5): e120-e122, doi: 10.1097/IOP.0000000000000842, indexed in Pubmed: 27930425.

20. Kamenetsky E, Nader A, Kendall MC. Use of peripheral nerve blocks with sedation for total knee arthroplasty in a patient with contraindication for general anesthesia. Case Rep Anesthesiol. 2015; 2015: 950872, doi: 10.1155/2015/950872, indexed in Pubmed: 26587290.

21. Kumari S, Chauhan $P$, Kathole $M$, et al. Pronator teres accessorius: a new variant in flexor antebrachial musculature. Morphologie. 2018; 102(336): 21-24, doi: 10.1016/j. morpho.2017.07.174, indexed in Pubmed: 28927574.

22. Kumka M. Critical sites of entrapment of the posterior division of the obturator nerve: anatomical considerations. J Can Chiropr Assoc. 2010; 54(1): 33-42, indexed in Pubmed: 20195424.

23. Kwon T, Kim H, Moon J, et al. Ultrasound guided both obturator nerve block for patient with adductor thigh muscle spasm: a case report-. Korean J Pain. 2009; 22(1): 78, doi: 10.3344/kjp.2009.22.1.78.

24. Larsen WJ. Anatomy: development, function, clinical correlations. WB Saunders, Philadelphia 2002.

25. Lee $\mathrm{SH}$, Jeong CW, Lee $\mathrm{HJ}$, et al. Ultrasound guided obturator nerve block: a single interfascial injection technique. J Anesth. 2011; 25(6): 923-926, doi: 10.1007/s00540011-1228-y, indexed in Pubmed: 21918855.

26. McMinn RMH, Hutchings RT, Pegington J, Abrahams PA. Colour Atlas of Human Anatomy. 3rd ed. Wolfe Publishing, London 1993.

27. Moore KL, Dalley AF, Agur AMR. Clinically Oriented Anatomy. 7th ed. Lippincott Williams \& Wilkins, Philadelphia 2014.

28. Mori M. Statistics on the musculature of the Japanese. Okajimas Folia Anat Jpn. 1964; 40: 195-300, doi: 10.2535/ ofaj1936.40.3 195, indexed in Pubmed: 14213705.

29. Nakamura E, Masumi S, Miura M, et al. A supernumerary muscle between the adductors brevis and minimus in humans. Okajimas Folia Anat Jpn. 1992; 69(2-3): 89-98, doi: 10.2535/ofaj1936.69.2-3_89, indexed in Pubmed: 1436954.

30. Ochiltree AB. Some muscular anomalies in the lower limb. J Anat Physiol. 1912; 47(Pt 1): 31-34, indexed in Pubmed: 17232941.

31. Paraskevas GK, Raikos A, loannidis O. Supernumerary semitendinosus muscle: $A$ rare case presentation and its 
clinical significance. Clin Anat. 2010; 23(8): 909-910, doi: 10.1002/ca.21029, indexed in Pubmed: 20830796.

32. Peiris WL, Cicuttini FM, Constantinou M, et al. Association between hip muscle cross-sectional area and hip pain and function in individuals with mild-to-moderate hip osteoarthritis: a cross-sectional study. BMC Musculoskelet Disord. 2020; 21(1): 316, doi: 10.1186/s12891-020-03348-5, indexed in Pubmed: 32438921.

33. Peragallo JH, Hudgins PA. Strabismus from supernumerary extraocular muscle restriction. Neurology. 2016; 87(18): 1958-1959, doi: 10.1212/WNL.0000000000003292, indexed in Pubmed: 27799476.

34. Pladzyk K, Jureczko L, Lazowski T. Over 500 obturator nerve blocks in the lithotomy position during transurethral resection of bladder tumor. Cent European J Urol. 2012; 65(2): 67-70, doi: 10.5173/ceju.2012.02.art2, indexed in Pubmed: 24578931.

35. Rha DW, Lee SH, Lee HJ, et al. Ultrasound-guided injection of the adductorlongus and pectineus in a cadaver model. Pain Physician. 2015; 18(6): E1111-E1117, doi: 10.36076/ ppj.2015/18/e1111.

36. Rohen JW, Yokochi C, Lütjen-Drecoll E. Color Atlas of Anatomy: A Photographic Study of the Human Body. 6th ed. Lippincott Williams \& Wilkins, Philadelphia 2006.

37. Romanes GJ. Cunningham's Textbook of Anatomy. 12th ed. Oxford University Press, Oxford 1981.

38. Sadler TW. Langman's Medical Embryology. 14th ed. Lippincott Williams \& Wilkins, Philadelphia 2019.

39. Salmons S. Muscle. In: Williams PL (ed.). Gray's Anatomy. Churchill Livingstone, New York 1995: 737-900.

40. Saluja S, Das SS, Kumar D, et al. Bilateral three-headed biceps brachii muscle and its clinical implications. Int J Appl Basic Med Res. 2017; 7(4): 266-268, doi: 10.4103/ ijabmr.IJABMR_339_16, indexed in Pubmed: 29308368.

41. Schüenke M, SchulteE, Schumacher U, Ross LM, Lamperti ED, Voll M. Atlas of Anatomy: General Anatomy and Musculoskeletal System. Thieme, Stuttgart 2006.

42. Sim IW, Webb T. Anatomy and anaesthesia of the lumbar somatic plexus. Anaesth Intensive Care. 2004; 32(2): 178-187, doi: 10.1177/0310057X0403200204, indexed in Pubmed: 15957714.

43. Sinha SK, Abrams JH, Houle TT, et al. Ultrasound-guided obturator nerve block: an interfascial injection approach without nerve stimulation. Reg Anesth Pain Med. 2009;
34(3): 261-264, doi: 10.1097/AAP.0b013e3181a32c4d, indexed in Pubmed: 19587627.

44. Šink Ž, Umek N, Cvetko E. Cross-over type of supernumerary digastric muscle. Folia Morphol. 2019; 78(3): 647-650, doi: 10.5603/FM.a2018.0112, indexed in Pubmed: 30536357.

45. Smith J, Pourcho AM, Kakar S. Sonographic appearance of the extensor carpi radialis intermedius tendon. PM R. 2015; 7(7): 789-791, doi: 10.1016/j.pmrj.2015.04.005, indexed in Pubmed: 25857593.

46. Song H, Kim J, Yoon SP. Coexistence of a pectoralis quartus muscle, a supernumerary head of biceps brachii muscle and an accessory head of flexor digitorum profundus muscle. Folia Morphol. 2019; 78(1): 204-207, doi: 10.5603/ FM.a2018.0048, indexed in Pubmed: 29802720.

47. Soong J, Schafhalter-Zoppoth I, Gray AT. Sonographic imaging of the obturator nerve for regional block. Reg Anesth Pain Med. 2007; 32(2): 146-151, doi: 10.1016/j. rapm.2006.10.012, indexed in Pubmed: 17350526.

48. Suk JIm, Walker FO, Cartwright MS. Ultrasonography of peripheral nerves. Curr Neurol Neurosci Rep. 2013; 13(2): 328, doi: 10.1007/s11910-012-0328-x, indexed in Pubmed: 23314937.

49. Tipton JS. Obturator neuropathy. Curr Rev Musculoskelet Med. 2008; 1(3-4): 234-237, doi: 10.1007/s12178-0089030-7, indexed in Pubmed: 19468309.

50. Tubbs RS, Griessenauer CJ, Marshall T, et al. The adductor minimus muscle revisited. Surg Radiol Anat. 2011; 33(5): 429-432, doi: 10.1007/s00276-010-0741-2, indexed in Pubmed: 21052670.

51. Yatsunami M, Tai T, Irie $Y$, et al. A morphological study on the human obturator externus muscle with reference to anomalous muscle and anomalous fasciculus originating from the obturator externus muscle. Okajimas Folia Anat Jpn. 2004; 80(5-6): 103-114, doi: 10.2535/ofaj.80.103, indexed in Pubmed: 15134328.

52. Yoshida T, Nakamoto T, Kamibayashi T. Ultrasound-Guided obturator nerve block: a focused review on anatomy and updated techniques. Biomed Res Int. 2017; 2017: 7023750, doi: 10.1155/2017/7023750, indexed in Pubmed: 28280738.

53. Yoshida T, Onishi T, Furutani K, et al. A new ultrasound-guided pubic approach for proximal obturator nerve block: clinical study and cadaver evaluation. Anaesthesia. 2016; 71(3): 291-297, doi: 10.1111/anae.13336, indexed in Pubmed: 26620274. 